\title{
Aplicação das Equações Diferenciais e da Transformada de Laplace em Circuitos Elétricos
}

\author{
Glaucia Maria Bressan Thiago de Souza Pinto \\ Leandro Naves de Oliveira* \\ Universidade Tecnológica Federal do Paraná \\ Av. Alberto Carazzai, 1640, CEP 863.000-000 \\ Câmpus Cornélio Procópio, PR \\ Coordenação do Curso de Matemática \\ E-mail: glauciabressan@utfpr.edu.br
}

\section{RESUMO}

O presente trabalho tem como principal objetivo a utilização da teoria matemática, em especial Equações Diferenciais e Transformada de Laplace, para compreensão de aplicações reais de pequeno porte que envolvam circuitos elétricos integrados.

A Transformada de Laplace é fundamental para o estudo de alguns fenômenos físicos. Por ser uma ferramenta muito eficiente de resolução de Equações Diferenciais Ordinárias Lineares de Segunda Ordem, a Transformada de Laplace é muito bem aplicada na análise da tensão de circuitos elétricos, cuja modelagem envolve este tipo de equação diferencial, como pode ser visto na referência [4].

Em geral, o método de Transformada de Laplace consiste em resolver equações diferenciais como se fossem equações algébricas ([1];[4]). Desta forma, pode-se chegar a uma função, de variável diferente da primeira, que possui uma determinada e desejável propriedade que a primeira função não possuía. Em seguida, fazendo o caminho inverso, o qual é chamado de transformada inversa, pode-se obter o resultado esperado para a primeira função, em sua variável original.

Desta forma, a tensão em um circuito do tipo RC (resistor-capacitor) série, por exemplo, é dada pela Equação (1)

$$
E(t)=\frac{1}{c} q+R \frac{d q}{d t}
$$

Ao transformar a Equação (1), aplicando Laplace, a equação resultante pode ser resolvida por métodos algébricos mais simples. A transformada inversa retorna, por sua vez, a solução procurada na variável $t$.

Os filtros contínuos são definidos como blocos lineares básicos formados por circuitos elétricos utilizados em diversos sistemas eletrônicos. A equação diferencial que define a forma de onda da saída, para um dado sinal de entrada, está implícita na função de transferência do filtro [2]. A forma mais simples de caracterizar o comportamento de um filtro é através do cálculo da sua Função de Transferência no domínio da transformada de Laplace, escrita na Equação (2).

$$
H(s)=\frac{V_{s}(s)}{V_{e}(s)}
$$

Ou seja, o estudo do bloco pode ser feito diretamente a partir da relação entre o sinal de saída $V_{s}(s)$ e o sinal de entrada $V_{\theta}(s)$. Este princípio básico da análise de sistemas lineares e invariantes no tempo permite simplificar e generalizar o estudo de qualquer circuito, independentemente da arquitetura interna utilizada para implementar o filtro. 
Os chamados filtros Passa-Baixa RC são circuitos eletrônicos que permitem a passagem de baixas frequências e reduz a amplitude das frequências maiores que a frequência de corte [3]. Sendo assim, estes circuitos filtram sons agudos, ou seja, de frequências altas e deixam passar sons de baixa frequência, os graves.

A Figura 1 ilustra uma descrição do circuito elétrico que representa um Filtro Passa-Baixa, onde $V_{\theta}$ é a tensão de entrada do circuito, $V_{s}$ é a tensão de saída do capacitor, $R$ o resistor, $C$ o capacitor e $i$ a corrente.

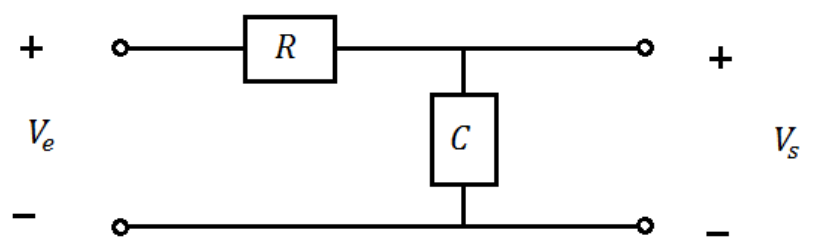

Figura 1. Circuito RC - Filtro Passa-Baixa.

A tensão de saída $V_{s}$ pode ser escrita em função de $V_{e}$ conforme a Equação (3)

$$
V_{s}=\frac{x_{C}}{R+X_{e}} V_{e}
$$

em que $X_{c}$ é a reatância capacitiva dada na Equação (4)

$$
X_{c}=\frac{1}{j \omega C} .
$$

Substituindo a Equação (4) na Equação (3), obtemos a Equação (5)

$$
\frac{V_{S}}{V_{e}}=\frac{1}{1+R j \omega C}=H(\omega)
$$

A Equação (5), indicada por $H(\omega)$, é a função transferência de um Filtro Passa-Baixa RC em função da frequência. Como $H(\omega)$ é uma função complexa e o ganho de tensão é o módulo da função de transferência na forma polar, e a fase é o ângulo da função de transferência, podemos escrever respectivamente a expressão para o ganho de tensão e fase para um Filtro Passa-Baixa $\mathrm{RC}$, conforme Equações (6) e (7)

$$
\begin{gathered}
G V=\frac{1}{\sqrt{1+(\omega R C)^{2}}} \\
\alpha=\operatorname{arctg}(\omega R C)
\end{gathered}
$$

Por meio da função transferência de um Filtro Passa-Baixa RC dada na Equação (5), pode-se descobrir a frequência de corte, ou frequência limite. Observando que a frequência de limite ocorre quando $G=\frac{1}{\sqrt{2}}$, então 


$$
\begin{aligned}
1+\left(\omega_{c} R C\right)^{2}=2 & \Rightarrow\left(\omega_{c} R C\right)^{2}=1 \\
& \Rightarrow \omega_{c}=\frac{1}{R C}
\end{aligned}
$$

Assim, a Equação (8) fornece a frequência de corte para um Filtro Passa-Baixa RC. Utilizando as Equações (7) e (8) tem-se que a fase na frequência de corte será igual a $\alpha=-45^{\circ}$.

Este trabalho está em fase final e pretende-se avançar os estudos para a Teoria de Resposta em Frequência (Função de Transferência, diagrama de Bode, Ressonância Série e Paralela e Filtros Passivos) e compreender aplicações como, por exemplo, Receptores de Rádio e Discagem por Tom.

Palavras-chave: Circuito RC, Filtros, Transformada de Laplace.

\section{Referências}

[1] K. Ogata. "Engenharia de Controle Moderno". 5a ed. Rio de Janeiro: Pearson Education, 2011.

[2] A.V. Oppenheim, A.S. Willsky, S.H. Nawab. "Signals and Systems". 2a ed. Prentice Hall, 1996.

[3] M. N. O. Sadiku, C.K. Alexander. "Fundamentos de Circuitos Elétricos". 5a. ed. McGraw Hill, 2013.

[4] D. G. Zill, M.R. Cullen. "Equações Diferenciais". 3ª ed. São Paulo: Makron Books, 2001. 